Research Article

\title{
Proposed Modification of the pN2 Classification of the 8th Edition AJCC Staging System for Esophageal Squamous Cell Carcinoma: A Preliminary Study Based on the Chinese Population
}

\author{
Kexing Xi $\mathbb{D}^{1,2,3}$ and Hui Yu $\mathbb{i D}^{2,3}$ \\ ${ }^{1}$ Department of Colorectal Surgery and State Key Lab of Molecular Oncology, \\ National Cancer Center/National Clinical Research Center for Cancer/Cancer Hospital, Chinese Academy of Medical Sciences \\ and Peking Union Medical College, Beijing 100021, China \\ ${ }^{2}$ Department of Thoracic Surgery, Sun Yat-sen University Cancer Center, Guangzhou 510060, China \\ ${ }^{3}$ State Key Laboratory of Oncology in South China, Collaborative Innovation Center for Cancer Medicine, \\ Guangzhou 510060, China
}

Correspondence should be addressed to Kexing Xi; xi_kexing@163.com and Hui Yu; yuhui@sysucc.org.cn

Received 21 August 2020; Revised 24 January 2021; Accepted 8 February 2021; Published 11 March 2021

Academic Editor: Prasannakumar Santhekadur

Copyright (c) 2021 Kexing Xi and Hui Yu. This is an open access article distributed under the Creative Commons Attribution License, which permits unrestricted use, distribution, and reproduction in any medium, provided the original work is properly cited.

\begin{abstract}
Objective. To evaluate the efficacy of the nodal staging of the 8th edition AJCC staging system for esophageal squamous cell carcinoma (ESCC) and propose a modification of the current pN2 classification. Methods. 1188 patients who underwent esophagectomy for ESCC at Sun Yat-sen University Cancer Center in Guangzhou (Guangdong, China) between January 2005 and June 2010 were reviewed. We used the X-tile software to determine the optimal cutoff points. Kaplan-Meier method and log-rank test were used to compare the differences of survival. Multivariate Cox regression analysis was performed for the factors that were statistically significant in univariate analysis. Result. In multivariate Cox regression analysis, alcohol consumption, pT status, and $\mathrm{pN}$ status were independent prognostic factors for overall survival (OS) according to the current $\mathrm{pN}$ classifications. And the observed 5-year OS rates for groups pN0, pN1, pN2, pN3 were $66.7 \%, 45.0 \%, 31.5 \%$, and $21.5 \%$, respectively $(P<0.001)$. Based on the above results, the current $\mathrm{pN} 2$ classification was further subdivided as pN2a [3 metastatic lymph nodes (LNs)] and pN2b (4-6 metastatic LNs) groups. The 5-year OS rates for groups pN0, pN1, pN2a, pN2b, and pN3 were 66.7\%, 45.0\%, 37.7\%, 26.3\% and $21.5 \%$, respectively $(P<0.001)$. The rate of 5 -year disease-free survival (DFS) was $60.0 \%$ for patients with pN0, compared with $36.8 \%, 29.3 \%, 20.8 \%$, and $14.3 \%$ for those with $\mathrm{pN} 1, \mathrm{pN} 2 \mathrm{a}, \mathrm{pN} 2 \mathrm{~b}$, and $\mathrm{pN} 3$, respectively $(P<0.001)$. The current pN2 classification should be subdivided as pN2a ( 3 metastatic LNs) and pN2b (4-6 metastatic LNs) groups. The modified pN2 classification could better discriminate the survival differences between patients with 3-6 metastatic LNs for ESCC in the Chinese population.
\end{abstract}

\section{Introduction}

Globally, esophagealcancer (EC) is the seventh most common diagnosed cancer and the sixth most frequent cause of cancer-related deaths $[1,2]$.The histological type of EC mainly consisted of squamous cellcarcinomaand adenocarcinoma [3]. In China, more than $90 \%$ of EC cases is squamous cell carcinoma $[4,5]$. The prognosis of EC is still unsatisfactory and the 5-year overall survival (OS) rate is not more than $25 \%[6,7]$.
Lymph node (LN) status is one of the most important factors for the prognosis of EC patients [8]. Tumor-nodemetastasis (TNM) staging system is applied to estimate prognosis and guide treatment plan making in clinical practice [9]. The current nodal staging system is based on the number of metastatic LNs. According to the eighth edition of the American Joint Committee on Cancer (AJCC) staging manual, the $\mathrm{pN}$ categories of $\mathrm{EC}$ are classified as pN0 (0), pN1 (1-2), pN2 (3-6), and pN3 ( $\geq 7)$ based on the number of metastatic LNs [10]. The current 
nodal staging system defines patients with 3-6 metastatic LNs as pN2, which is too general. The previous studies have demonstrated that the number of metastatic LNs is significantly associated with prognosis of EC [11-13]. Thus, the current pN2 classification should be divided into more subgroups.

In this study, data were collected from a large cohort of Chinese patients in a high-volume institution. We aimed to provide a proposal to subdivide the current $\mathrm{pN} 2$ classification, which could provide more prognostic information for esophageal squamous cellcarcinoma (ESCC) patients in the Chinese population.

\section{Patients and Methods}

2.1. Patients Selection. Patients who underwent esophagectomy for ESCC at Sun Yat-sen University Cancer Center in Guangzhou (Guangdong, China) between January 2005 and June 2010 were reviewed. This study was approved by the Ethics Committee of Sun Yat-sen University Cancer Center.

Patients were included based on the following eligibility criterion: patients who underwent radical esophagectomy with pathologically confirmed ESCC. Patients were not eligible according to the following criteria: (1) diagnosed with not squamous cell carcinoma; (2) patients with preoperative therapy, including radiotherapy, chemotherapy, or chemoradiotherapy; (3) patients who underwent R1/R2 resection; (4) patients with a second tumor; (5) those who died within 30 days of surgery; (6) patients with carcinoma in situ; (7) patients with incomplete clinicopathologic information; and (8) patients with distant metastasis. Finally, 1188 patients were included in the present study (Figure 1).

2.2. Follow-Up. All patients were followed up after surgery every 3 months for the first year, every 6 months for the next 2 years, and annually thereafter. The follow-up examinations including thoracoabdominal CT, endoscopy, tumor markers, and barium esophagography. The last follow-up date was conducted at July 1,2015 . The interval between the date of surgery and the date of death or the last follow-up was defined as overall survival (OS) time. The disease-free survival (DFS) was defined as the time period from surgery to the appearance of tumor progression or the date of cancer-related death.

2.3. Statistical Analysis. Statistical analyses were performed using SPSS 25.0 software (SPSS Inc., Chicago, IL, USA). The optimal cutoff points were identified using the X-tile software (version 3.6.1, Copyright Yale University, 2003) [14]. $\mathrm{X}$-tile software determined the best cutoff points by using the minimum $p$ value. Kaplan-Meier method and log-rank test were used to compare the differences of survival. Multivariate Cox regression analysis was performed for the factors that were statistically significant in univariate analysis. A two-tailed $P$ value $<0.05$ was considered statistically significant.

\section{Results}

A total of 1188 patients with ESCC were enrolled in this study, including 928 male patients and 260 female patients. The mean and median age of all patients were 58.4 and 58.0 years, respectively (range, 30-88 years). 616 (51.9\%) patients without metastatic LN and 572 (48.1\%) had LN metastasis (Table 1). The number of N0, N1, N2, and N3 patients was 616 (51.9\%), 319 (26.9\%), 204 (17.2\%), and 49 (4.1\%), respectively.

Cox univariate and multivariate analyses were used to evaluate the prognostic factors of OS based on the current $\mathrm{pN}$ classifications. Univariate analysis demonstrated that smoking status, alcohol consumption, tumor length, pT status, $\mathrm{pN}$ status, and differentiation were independent prognostic factors of OS. In multivariate analysis, only alcohol consumption, tumor length, $\mathrm{pT}$ status, and $\mathrm{pN}$ status were independent prognostic factors (Table 1). Kaplan-Meier curves were applied to compare the survival rates among different $\mathrm{pN}$ groups. The analysis results demonstrated that the observed 5-year OS rates for groups pN0, pN1, pN2, and $\mathrm{pN} 3$ were $66.7 \%, 45.0 \%, 31.5 \%$, and $21.5 \%$, respectively $(P<0.001$, Figure 2$)$. The 5 -year OS rate was significantly worse with the increasing $\mathrm{pN}$ classifications.

Based on the above results, the current $\mathrm{pN} 2$ classification was further subdivided as pN2a (3 metastatic LNs) and pN2b (4-6 metastatic LNs) groups by using the X-tile software (Figure 3). Based on the revised $\mathrm{pN}$ classifications, univariate and multivariate analyses were performed to identify the risk factors of OS and DFS. In univariate analysis, smoking status, alcohol consumption, tumor length, pT status, revised $\mathrm{pN}$ status, and differentiation were associated with $\mathrm{OS}$ and DFS significantly. However, only alcohol consumption, tumor length, pT status, and revised $\mathrm{pN}$ status were independent prognostic factors of OS in multivariate analysis (Table 2). Moreover, only tumor length, pT status, and revised $\mathrm{pN}$ status were significantly associated with DFS in multivariate analysis (Table 3). The 5-year OS and DFS rates based on the revised $\mathrm{pN}$ classifications were shown in Figures 4(a) and 4(b). The 5-year OS rates for groups pN0, pN1, pN2a, pN2b, and pN3 were 66.7\%, 45.0\%, 37.7\%, $26.3 \%$, and $21.5 \%$, respectively $(P<0.001)$. The rate of 5 -year DFS was $60.0 \%$ for patients with pN0, compared with $36.8 \%$, $29.3 \%, 20.8 \%$, and $14.3 \%$ for those with pN1, pN2a, pN2b, and $\mathrm{pN} 3$, respectively $(P<0.001)$. Increased $\mathrm{pN}$ classifications demonstrated significantly decreased survival.

\section{Discussion}

LN status is an important prognostic factor for EC patients. In clinical practice, the 8th edition AJCC classification system is widely applied in staging of EC. The 8th nodal staging defines 3-6 metastatic LNs as pN2 in EC, which is too general and could not provide more detail of the survival information.

In the present study, we validated the current $\mathrm{pN}$ classifications of the 8th edition AJCC classification system in the first stage and found that there were significant differences in survival between different $\mathrm{pN}$ 


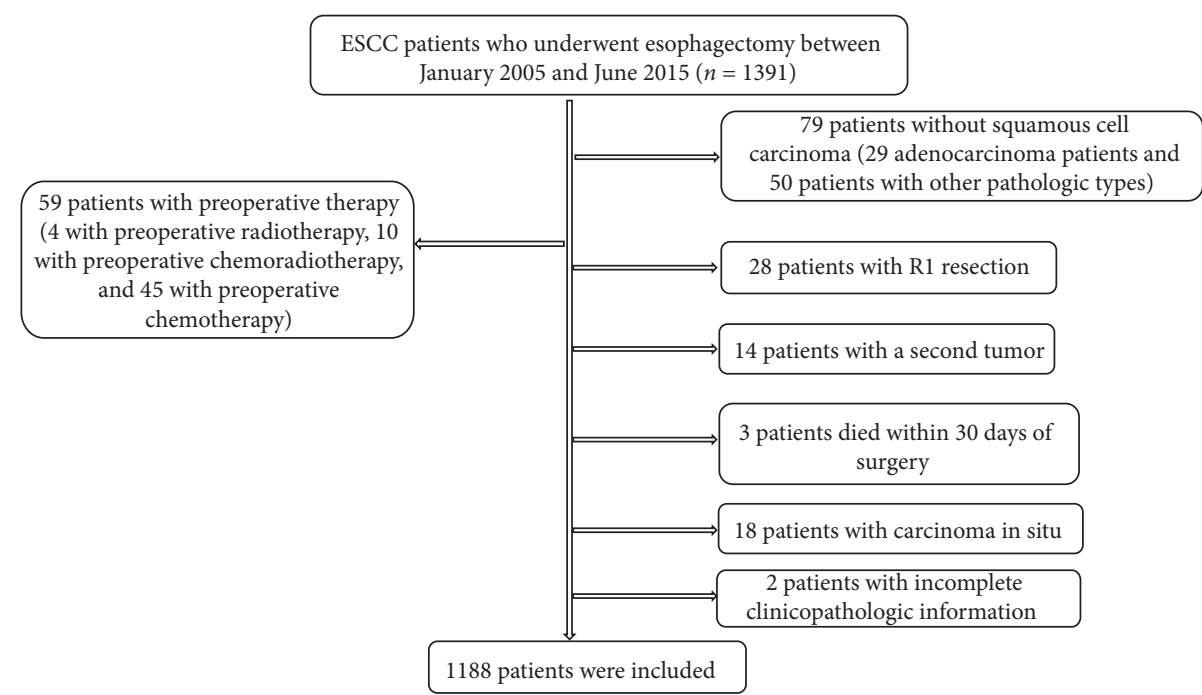

Figure 1: Selection flow of 1188 ESCC patients.

TABLE 1: Univariate and multivariate Cox regression analyses of prognostic factors for OS in 1188 ESCC patients based on the 8th edition AJCC nodal staging.

\begin{tabular}{|c|c|c|c|c|c|}
\hline \multirow{2}{*}{ Variable } & \multirow{2}{*}{$N(\%)$} & \multicolumn{2}{|c|}{ Univariate analysis } & \multicolumn{2}{|c|}{ Multivariate analysis } \\
\hline & & HR (95\% CI) & $P$ & HR $(95 \%$ CI) & $P$ \\
\hline Gender & & & 0.481 & & \\
\hline Male & $928(78.1)$ & Reference & & & \\
\hline Female & $260(21.9)$ & $0.932(0.765-1.134)$ & & & \\
\hline Age (years) & & & 0.063 & & \\
\hline$\leq 65$ & $935(78.7)$ & Reference & & & \\
\hline$>65$ & $253(21.3)$ & $1.199(0.990-1.452)$ & & & \\
\hline Smoking status & & & 0.025 & & \\
\hline Never & $420(35.4)$ & Reference & & & \\
\hline Former & $768(64.6)$ & $1.219(1.025-1.450)$ & & & \\
\hline Alcohol consumption & & & $<0.001$ & & 0.005 \\
\hline No & $924(77.8)$ & Reference & & Reference & \\
\hline Yes & $264(22.2)$ & $1.431(1.192-1.718)$ & & $1.301(1.082-1.564)$ & \\
\hline Tumor length $(\mathrm{cm})$ & & & $<0.001$ & & 0.043 \\
\hline$\leq 3$ & $317(26.7)$ & Reference & & Reference & \\
\hline $3-5$ & $364(30.6)$ & $1.217(0.972-1.523)$ & 0.086 & $0.796(0.626-1.013)$ & 0.064 \\
\hline$\geq 5$ & $507(42.7)$ & $1.523(1.242-1.869)$ & $<0.001$ & $1.001(0.801-1.251)$ & 0.992 \\
\hline Tumor location & & & 0.282 & & \\
\hline Upper & $117(9.8)$ & Reference & & & \\
\hline Middle & $761(64.1)$ & $1.128(0.851-1.497)$ & 0.402 & & \\
\hline Lower & $310(26.1)$ & $0.974(0.712-1.332)$ & 0.869 & & \\
\hline pT status & & & $<0.001$ & & $<0.001$ \\
\hline $\mathrm{T} 1$ & $119(10.0)$ & Reference & & Reference & \\
\hline $\mathrm{T} 2$ & $232(19.5)$ & $2.212(1.456-3.358)$ & $<0.001$ & $1.937(1.260-2.979)$ & 0.003 \\
\hline T3 & $796(67.0)$ & $2.968(2.024-4.352)$ & $<0.001$ & $2.381(1.575-3.599)$ & $<0.001$ \\
\hline $\mathrm{T} 4$ & $41(3.5)$ & $6.071(3.608-10.215)$ & $<0.001$ & $4.296(2.474-7.459)$ & $<0.001$ \\
\hline $\mathrm{pN}$ status & & & $<0.001$ & & $<0.001$ \\
\hline N0 & $616(51.9)$ & Reference & & Reference & \\
\hline $\mathrm{N} 1$ & $319(26.9)$ & $1.880(1.545-2.288)$ & $<0.001$ & $1.742(1.428-2.124)$ & $<0.001$ \\
\hline $\mathrm{N} 2$ & $204(17.2)$ & $2.861(2.309-3.546)$ & $<0.001$ & $2.514(2.019-3.130)$ & $<0.001$ \\
\hline $\mathrm{N} 3$ & $49(4.1)$ & $4.051(2.889-5.681)$ & $<0.001$ & $3.683(2.616-5.184)$ & $<0.001$ \\
\hline Differentiation & & & 0.024 & & \\
\hline Well & $253(21.3)$ & Reference & & & \\
\hline Moderate & $587(49.4)$ & $1.155(0.928-1.438)$ & 0.195 & & \\
\hline Poor & $347(29.2)$ & $1.374(1.086-1.737)$ & 0.008 & & \\
\hline
\end{tabular}


TABLE 1: Continued.

\begin{tabular}{|c|c|c|c|c|c|}
\hline \multirow{2}{*}{ Variable } & \multirow{2}{*}{$N(\%)$} & \multicolumn{2}{|c|}{ Univariate analysis } & \multicolumn{2}{|c|}{ Multivariate analysis } \\
\hline & & HR $(95 \%$ CI $)$ & $P$ & HR (95\% CI) & $P$ \\
\hline Surgical approach & & & 0.146 & & \\
\hline Left thoracotomy & $762(64.1)$ & Reference & & & \\
\hline Right thoracotomy & $426(35.9)$ & $0.881(0.742-1.045)$ & & & \\
\hline Anastomosis & & & 0.659 & & \\
\hline Hand-sewn & $168(14.1)$ & Reference & & & \\
\hline Stapled & $1020(85.9)$ & $0.950(0.755-1.194)$ & & & \\
\hline Adjuvant therapy & & & 0.469 & & \\
\hline No & $987(83.1)$ & Reference & & & \\
\hline Yes & $201(16.9)$ & $1.083(0.872-1.345)$ & & & \\
\hline Number of resected LNs & & & 0.073 & & \\
\hline$<15$ & $357(30.1)$ & Reference & & & \\
\hline$\geq 15$ & $831(69.9)$ & $0.854(0.719-1.015)$ & & & \\
\hline
\end{tabular}

HR: hazard ratio, CI: confidence interval, LNs: lymph nodes, and OS: overall survival.

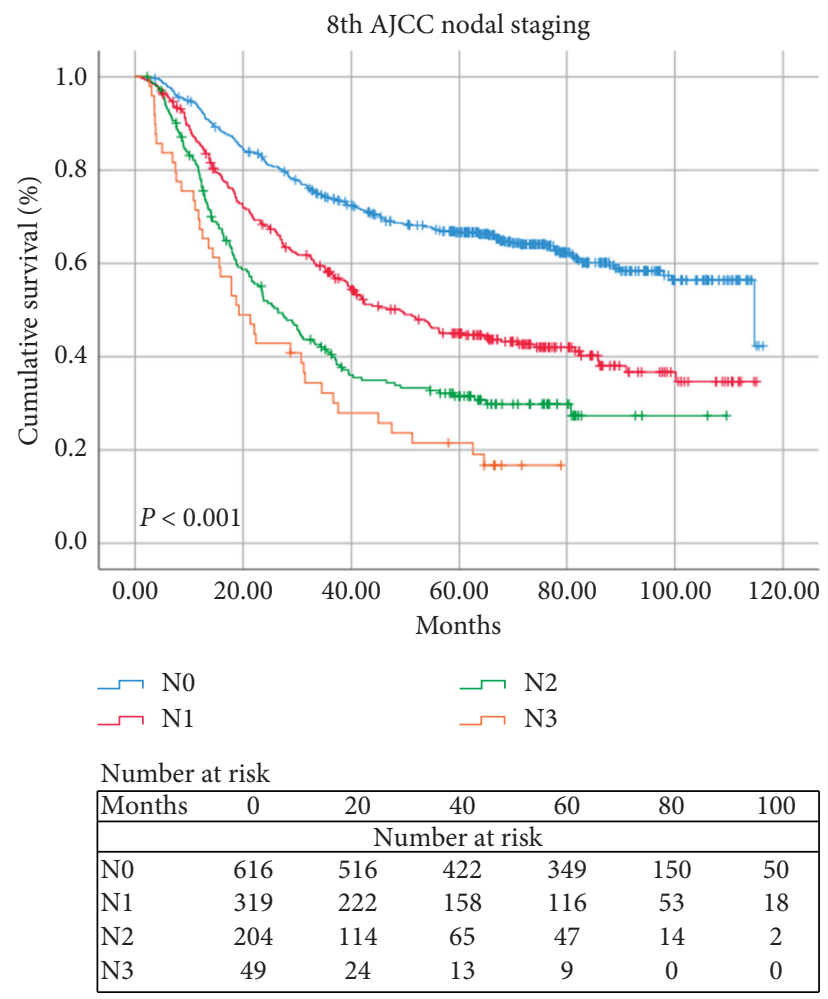

FIgURE 2: Kaplan-Meier survival curves for OS of 1188 ESCC patients based on the 8th edition AJCC nodal staging.

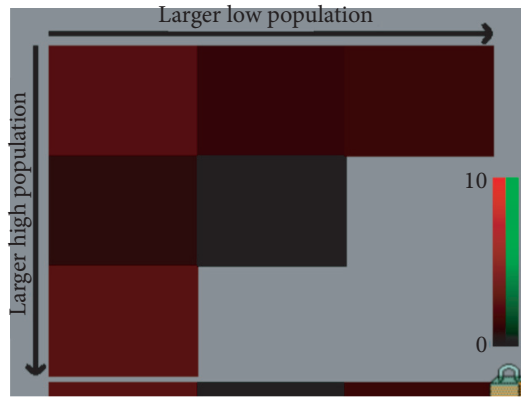

(a)

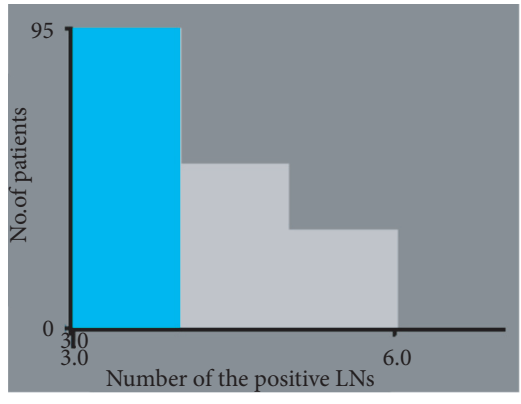

(b)

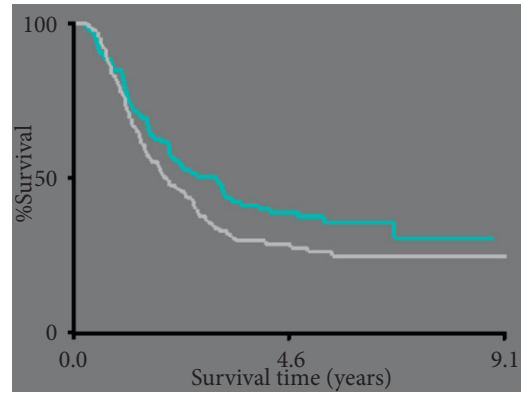

(c)

Figure 3: X-tile analysis for the optimal cutoff points. 
TABLE 2: Univariate and multivariate Cox regression analyses of prognostic factors for OS in 1188 ESCC patients based on the 8th edition AJCC nodal staging.

\begin{tabular}{|c|c|c|c|c|c|}
\hline \multirow{2}{*}{ Variable } & \multirow{2}{*}{$N(\%)$} & \multicolumn{2}{|c|}{ Univariate analysis } & \multicolumn{2}{|c|}{ Multivariate analysis } \\
\hline & & HR $(95 \% \mathrm{CI})$ & $P$ & HR (95\% CI) & $P$ \\
\hline Gender & & & 0.481 & & \\
\hline Male & $928(78.1)$ & Reference & & & \\
\hline Female & $260(21.9)$ & $0.932(0.765-1.134)$ & & & \\
\hline Age (years) & & & 0.063 & & \\
\hline$\leq 65$ & $935(78.7)$ & Reference & & & \\
\hline$>65$ & $253(21.3)$ & $1.199(0.990-1.452)$ & & & \\
\hline Smoking status & & & 0.025 & & \\
\hline Never & $420(35.4)$ & Reference & & & \\
\hline Former & $768(64.6)$ & $1.219(1.025-1.450)$ & & & \\
\hline Alcohol consumption & & & $<0.001$ & & 0.007 \\
\hline No & $924(77.8)$ & Reference & & Reference & \\
\hline Yes & $264(22.2)$ & $1.431(1.192-1.718)$ & & $1.289(1.072-1.550)$ & \\
\hline Tumor length $(\mathrm{cm})$ & & & $<0.001$ & & 0.036 \\
\hline$\leq 3$ & $317(26.7)$ & Reference & & Reference & \\
\hline $3-5$ & $364(30.6)$ & $1.217(0.972-1.523)$ & 0.086 & $0.800(0.628-1.017)$ & 0.069 \\
\hline$\geq 5$ & $507(42.7)$ & $1.523(1.242-1.869)$ & $<0.001$ & $1.017(0.813-1.271)$ & 0.886 \\
\hline Tumor location & & & 0.282 & & \\
\hline Upper & $117(9.8)$ & Reference & & & \\
\hline Middle & $761(64.1)$ & $1.128(0.851-1.497)$ & 0.402 & & \\
\hline Lower & $310(26.1)$ & $0.974(0.712-1.332)$ & 0.869 & & \\
\hline pT status & & & $<0.001$ & & $<0.001$ \\
\hline $\mathrm{T} 1$ & $119(10.0)$ & Reference & & Reference & \\
\hline $\mathrm{T} 2$ & $232(19.5)$ & $2.212(1.456-3.358)$ & $<0.001$ & $1.944(1.264-2.989)$ & 0.002 \\
\hline T3 & $796(67.0)$ & $2.968(2.024-4.352)$ & $<0.001$ & $2.368(1.567-3.580)$ & $<0.001$ \\
\hline $\mathrm{T} 4$ & $41(3.5)$ & $6.071(3.608-10.215)$ & $<0.001$ & $4.425(2.547-7.689)$ & $<0.001$ \\
\hline $\mathrm{pN}$ status & & & $<0.001$ & & $<0.001$ \\
\hline No & $616(51.9)$ & Reference & & Reference & \\
\hline N1 & $319(26.9)$ & $1.881(1.546-2.289)$ & $<0.001$ & $1.742(1.429-2.125)$ & $<0.001$ \\
\hline $\mathrm{N} 2 \mathrm{a}$ & $95(8.0)$ & $2.445(1.831-3.266)$ & $<0.001$ & $2.104(1.567-2.826)$ & $<0.001$ \\
\hline $\mathrm{N} 2 \mathrm{~b}$ & $109(9.2)$ & $3.280(2.531-4.251)$ & $<0.001$ & $2.936(2.256-3.821)$ & $<0.001$ \\
\hline N3 & $49(4.1)$ & $4.054(2.891-5.685)$ & $<0.001$ & $3.688(2.620-5.191)$ & $<0.001$ \\
\hline Differentiation & & & 0.024 & & \\
\hline Well & $253(21.3)$ & Reference & & & \\
\hline Moderate & $587(49.4)$ & $1.155(0.928-1.438)$ & 0.195 & & \\
\hline Poor & $347(29.2)$ & $1.374(1.086-1.737)$ & 0.008 & & \\
\hline Surgical approach & & & 0.146 & & \\
\hline Left thoracotomy & $762(64.1)$ & Reference & & & \\
\hline Right thoracotomy & $426(35.9)$ & $0.881(0.742-1.045)$ & & & \\
\hline Anastomosis & & & 0.659 & & \\
\hline Hand-sewn & $168(14.1)$ & Reference & & & \\
\hline Stapled & $1020(85.9)$ & $0.950(0.755-1.194)$ & & & \\
\hline Adjuvant therapy & & & 0.469 & & \\
\hline No & $987(83.1)$ & Reference & & & \\
\hline Yes & $201(16.9)$ & $1.083(0.872-1.345)$ & & & \\
\hline Number of resected LNs & & & 0.073 & & \\
\hline$<15$ & $357(30.1)$ & Reference & & & \\
\hline$\geq 15$ & $831(69.9)$ & $0.854(0.719-1.015)$ & & & \\
\hline
\end{tabular}

HR: hazard ratio, CI: confidence interval, LNs: lymph nodes, and OS: overall survival.

groups. After that, the current pN2 classification was subdivided as $\mathrm{pN} 2 \mathrm{a}$ and $\mathrm{pN} 2 \mathrm{~b}$ groups. What was more, patients with $\mathrm{pN} 2 \mathrm{a}$ had a better survival than those with pN2b significantly and significant survival differences existed between each revised $\mathrm{pN}$ classification. The results of our study showed that the revised pN2 classifications could provide more accurate prognosis information for EC patients.

As a reasonable nodal classification system, there should be a higher predictive value for prognosis and a different 
TABLE 3: Univariate and multivariate Cox regression analyses of prognostic factors for DFS in 1188 ESCC patients based on the revised pN classifications.

\begin{tabular}{|c|c|c|c|c|c|}
\hline \multirow{2}{*}{ Variable } & \multirow{2}{*}{$N(\%)$} & \multicolumn{2}{|c|}{ Univariate analysis } & \multicolumn{2}{|c|}{ Multivariate analysis } \\
\hline & & HR (95\% CI) & $P$ & HR $(95 \%$ CI $)$ & $P$ \\
\hline Gender & & & 0.319 & & \\
\hline Male & $928(78.1)$ & Reference & & & \\
\hline Female & $260(21.9)$ & $0.909(0.755-1.096)$ & & & \\
\hline Age (years) & & & 0.596 & & \\
\hline$\leq 65$ & $935(78.7)$ & Reference & & & \\
\hline$>65$ & $253(21.3)$ & $1.051(0.874-1.265)$ & & & \\
\hline Smoking status & & & 0.048 & & \\
\hline Never & $420(35.4)$ & Reference & & & \\
\hline Former & $768(64.6)$ & $1.178(1.001-1.386)$ & & & \\
\hline Alcohol consumption & & & 0.001 & & \\
\hline No & $924(77.8)$ & Reference & & & \\
\hline Yes & $264(22.2)$ & $1.334(1.119-1.591)$ & & & \\
\hline Tumor length $(\mathrm{cm})$ & & & $<0.001$ & & 0.008 \\
\hline$\leq 3$ & $317(26.7)$ & Reference & & Reference & \\
\hline $3-5$ & $364(30.6)$ & $1.142(0.926-1.408)$ & 0.215 & $0.795(0.635-0.997)$ & 0.047 \\
\hline$\geq 5$ & $507(42.7)$ & $1.468(1.213-1.778)$ & $<0.001$ & $1.052(0.853-1.297)$ & 0.635 \\
\hline Tumor location & & & 0.300 & & \\
\hline Upper & $117(9.8)$ & Reference & & & \\
\hline Middle & $761(64.1)$ & $1.004(0.775-1.301)$ & 0.978 & & \\
\hline Lower & $310(26.1)$ & $0.870(0.652-1.160)$ & 0.343 & & \\
\hline pT status & & & $<0.001$ & & $<0.001$ \\
\hline $\mathrm{T} 1$ & $119(10.0)$ & Reference & & Reference & \\
\hline $\mathrm{T} 2$ & $232(19.5)$ & $1.995(1.387-2.869)$ & $<0.001$ & $1.761(1.208-2.566)$ & 0.003 \\
\hline T3 & $796(67.0)$ & $2.416(1.735-3.363)$ & $<0.001$ & $1.916(1.334-2.751)$ & $<0.001$ \\
\hline $\mathrm{T} 4$ & $41(3.5)$ & $4.495(2.783-7.259)$ & $<0.001$ & $3.210(1.930-5.338)$ & $<0.001$ \\
\hline $\mathrm{pN}$ status & & & $<0.001$ & & $<0.001$ \\
\hline N0 & $616(51.9)$ & Reference & & Reference & \\
\hline N1 & $319(26.9)$ & $1.957(1.628-2.353)$ & $<0.001$ & $1.877(1.558-2.261)$ & $<0.001$ \\
\hline $\mathrm{N} 2 \mathrm{a}$ & $95(8.0)$ & $2.431(1.850-3.193)$ & $<0.001$ & $2.140(1.621-2.826)$ & $<0.001$ \\
\hline $\mathrm{N} 2 \mathrm{~b}$ & $109(9.2)$ & $3.177(2.483-4.066)$ & $<0.001$ & $3.020(2.351-3.878)$ & $<0.001$ \\
\hline N3 & $49(4.1)$ & $4.353(3.147-6.021)$ & $<0.001$ & $4.088(2.941-5.682)$ & $<0.001$ \\
\hline Differentiation & & & 0.015 & & \\
\hline Well & $253(21.3)$ & Reference & & & \\
\hline Moderate & $587(49.4)$ & $1.157(0.942-1.421)$ & 0.165 & & \\
\hline Poor & $347(29.2)$ & $1.373(1.101-1.713)$ & 0.005 & & \\
\hline Surgical approach & & & 0.348 & & \\
\hline Left thoracotomy & $762(64.1)$ & Reference & & & \\
\hline Right thoracotomy & $426(35.9)$ & $0.926(0.788-1.088)$ & & & \\
\hline Anastomosis & & & 0.676 & & \\
\hline Handsewn & $168(14.1)$ & Reference & & & \\
\hline Stapled & $1020(85.9)$ & $0.954(0.767-1.188)$ & & & \\
\hline Adjuvant therapy & & & 0.129 & & \\
\hline No & $987(83.1)$ & Reference & & & \\
\hline Yes & $201(16.9)$ & $1.168(0.956-1.428)$ & & & \\
\hline Number of resected LNs & & & 0.197 & & \\
\hline$<15$ & $357(30.1)$ & Reference & & & \\
\hline$\geq 15$ & $831(69.9)$ & $0.898(0.762-1.058)$ & & & \\
\hline
\end{tabular}

HR: hazard ratio, CI: confidence interval, LNs: lymph nodes, and DFS: disease-free survival.

survival rate between each group. Although the current nodal staging provided a more exact evaluation of survival than the sixth edition, it had not the ability to distinguish the survival of EC patients with 3-6 metastatic LNs [15]. However, the revised pN2 classification showed a good discriminatory ability for survival in these patients. The current pN2 classification of EC did not consider the effect of the specified number of metastatic LNs, which might not be perfect.

Previous studies demonstrated that a nodal staging system based on the number of metastatic LNs may be more sensitive for the survival estimation for EC than 


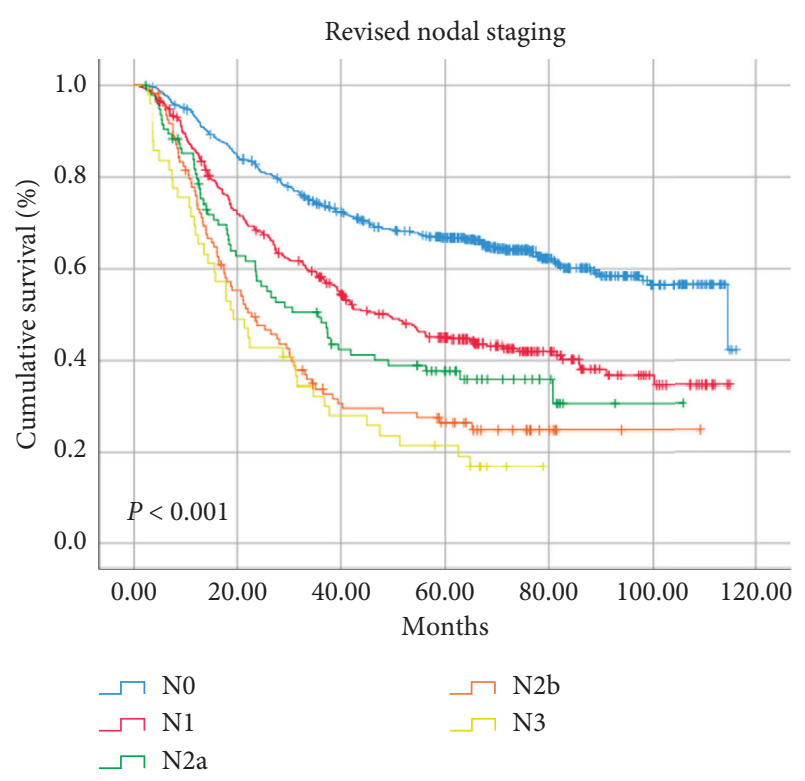

Number at risk
\begin{tabular}{|lcccccc|}
\hline Months & 0 & 20 & 40 & 60 & 80 & 100 \\
\hline Number at risk \\
\hline N0 & 616 & 516 & 422 & 349 & 150 & 50 \\
N1 & 319 & 222 & 158 & 116 & 53 & 18 \\
N2a & 95 & 56 & 36 & 25 & 8 & 1 \\
N2b & 109 & 58 & 29 & 22 & 6 & 1 \\
N3 & 49 & 24 & 13 & 9 & 0 & 0 \\
\hline
\end{tabular}

(a)

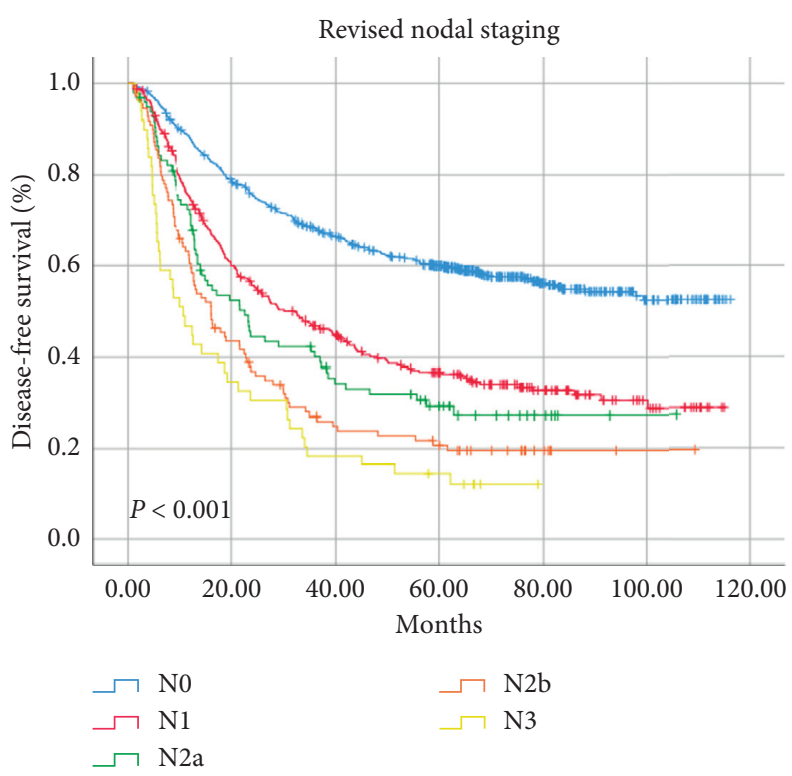

Number at risk

\begin{tabular}{|lcccccc|}
\hline Months & 0 & 20 & 40 & 60 & 80 & 100 \\
\hline Number at risk \\
\hline N0 & 616 & 479 & 381 & 308 & 136 & 49 \\
N1 & 319 & 184 & 128 & 91 & 45 & 17 \\
N2a & 95 & 47 & 29 & 19 & 6 & 1 \\
N2b & 109 & 46 & 24 & 19 & 6 & 1 \\
N3 & 49 & 17 & 9 & 6 & 0 & 0 \\
\hline
\end{tabular}

(b)

Figure 4: (a) Kaplan-Meier survival curves for OS of 1188 ESCC patients based on the revised nodal staging. (b) Kaplan-Meier survival curves for DFS of 1188 ESCC patients based on the revised nodal staging.

classification based on the location of LNs [16-18]. Compared with other indicators such as LN ratio (LNR, the ratio between the number of metastatic LNs and the total number of examined LNs) and log odds ratio (LODDS, the log of the ratio between the number of positive LNs and the number of negative LNs), the indicator-the number of metastatic LNs - was simpler and thus easy to generalize. Thus, our proposal to subdivide the $\mathrm{pN} 2$ classification was still based on the number of metastatic LNs.

In univariate and multivariate analyses, we also found that alcohol consumption was an independent prognostic factor of survival. This was consistent with previous studies $[19,20]$. However, no significant survival differences were observed between the patients with $<15$ LNs examined and those with $\geq 15$ LNs examined $(P=0.073)$. This might be because of the sample size of this study and the bias of retrospective study. The $P$ value (0.073) was closed to 0.05 and we thought that, with the sample size increased, there would be significant survival differences between these two groups.

It is well known that the clinicopathological features of EC vary widely between patients in Asian and Western countries [21]. Squamous cell carcinoma is the most common pathological type in China, and it is considered that more data from Chinese patients are essential to validate the generalizability of the 8th edition AJCC nodal staging system for ESCC [5]. A relatively large sample size solely from Chinese ESCC patients in one institution was included in this study, which could help to decrease the heterogeneous characteristics. Additionally, we determined the optimal cutoff values using the X-tile, which was one of the most convenient and objective methods $[14,22]$. As such, the results from our data were more precise and significant, which could better represent the prognostic characteristics of ESCC in the Chinese population.

Some limitations in the present study should be acknowledged. Firstly, the bias of a retrospective investigation was unavoidable. Secondly, the number of $\mathrm{pN} 3$ cases was small, which implied that the results needed further validation. This was a preliminary study based on single-center and we planned to enroll other databases to verify the conclusion and further subgroup the pN2 classification next. 
In conclusion, we proposed a modification of the current pN2 classification for ESCC. The modified pN2 classification could better discriminate the survival differences between patients with 3-6 metastatic LNs for ESCC in the Chinese population.

\section{Data Availability}

We may balance the potential benefits and risks for each request and then provide the data that could be shared.

\section{Conflicts of Interest}

The authors declare that they have no conflicts of interest.

\section{References}

[1] LA Torre, F. Bray, RL Siegel, J. Ferlay, J. Lortet-Tieulent, and A. Jemal, "Global cancer statistics," CA Cancer J Clin, vol. 65, no. 2 , pp. 87-108, 2012.

[2] World Health Organization.International Agency for Research on Cancer, GLOBOCAN 2018 oesophagus cancer fact sheet, 2018.

[3] J. R. Siewert and K. Ott, "Are squamous and adenocarcinomas of the esophagus the same disease?" Seminars in Radiation Oncology, vol. 17, no. 1, pp. 38-44, 2007.

[4] Y. Xu, X. Yu, Q. Chen, and W. Mao, "Neoadjuvant versus adjuvant treatment: which one is better for resectable esophageal squamous cell carcinoma?" World Journal of Surgical Oncology, vol. 10, no. 1, p. 173, 2012.

[5] S. Law and J. Wong, "Changing disease burden and management issues for esophageal cancer in the Asia-Pacific region," Journal of Gastroenterology and Hepatology, vol. 17, no. 4, pp. 374-381, 2002.

[6] M. Worni, J. Martin, B. Gloor et al., "Does surgery improve outcomes for esophageal squamous cell carcinoma? An analysis using the surveillance epidemiology and end results registry from 1998 to 2008," Journal of the American College of Surgeons, vol. 215, no. 5, pp. 643-651, 2012.

[7] P. C. Wu and M. C. Posner, "The role of surgery in the management of oesophageal cancer," The Lancet Oncology, vol. 4, no. 8, pp. 481-488, 2003.

[8] J. A. Ajani, T. A. D’Amico, D. J. Bentrem et al., "Esophageal and Esophagogastric Junction Cancers, Version 2.2019, NCCN Clinical Practice Guidelines in Oncology," Journal of the National Comprehensive Cancer Network, vol. 17, no. 7, pp. 855-883, 2019.

[9] T. W. Rice, V. W. Rusch, C. Apperson-Hansen et al., "Worldwide esophageal cancer collaboration," Diseases of the Esophagus, vol. 22, no. 1, pp. 1-8, 2009.

[10] MB Amin, S. Edge, F. Greene et al., Eds., American Joint Committee on Cancer (AJCC) Cancer Staging Manual, Springer International, New York, 8th edition, 2017.

[11] H.-L. Zhang, L.-Q. Chen, R.-L. Liu et al., "The number of lymph node metastases influences survival and International Union Against Cancer tumor-node-metastasis classification for esophageal squamous cell carcinoma," Diseases of the Esophagus, vol. 23, no. 1, pp. 53-58, 2010.

[12] J. Chen, J. Pan, X. Zheng et al., "Number and location of positive nodes, postoperative radiotherapy, and survival after esophagectomy with three-field lymph node dissection for thoracic esophageal squamous cell carcinoma," International
Journal of Radiation Oncology*Biology*Physics, vol. 82, no. 1, pp. 475-482, 2012.

[13] C. G. Peyre, J. A. Hagen, S. R. DeMeester et al., "Predicting Systemic Disease in Patients With Esophageal Cancer After Esophagectomy," Annals of Surgery, vol. 248, no. 6, pp. 979-985, 2008.

[14] R. L. Camp, M. Dolled-Filhart, and D. L. Rimm, "X-tile: a new bio-informatics tool for biomarker assessment and outcomebased cut-point optimization," Clinical Cancer Research, vol. 10, no. 21, pp. 7252-7259, 2004.

[15] FL Greene et al., "Esophagus," in American Joint Committee on Cancer (AJCC) Cancer Staging Manual, pp. 167-78, Springer, New York, 6th edition, 2002.

[16] B. P. L. Wijnhoven, K. T. C. Tran, A. Esterman, D. I. Watson, and H. W. Tilanus, "An evaluation of prognostic factors and tumor staging of resected carcinoma of the esophagus," Annals of Surgery, vol. 245, no. 5, pp. 717-725, 2007.

[17] C. Kunisaki, H. Akiyama, M. Nomura et al., "Developing an appropriate staging system for esophageal carcinoma," Journal of the American College of Surgeons, vol. 201, no. 6, pp. 884-890, 2005.

[18] H. Shimada, S.-i. Okazumi, H. Matsubara et al., "Impact of the number and extent of positive lymph nodes in 200 patients with thoracic esophageal squamous cell carcinoma after threefield lymph node dissection," World Journal of Surgery, vol. 30, no. 8, pp. 1441-1449, 2006.

[19] B. Secretan, K. Straif, R. Baan et al., "A review of human carcinogens-Part E: tobacco, areca nut, alcohol, coal smoke, and salted fish," The Lancet Oncology, vol. 10, no. 11, pp. 1033-1034, 2009.

[20] J. Steevens, L. J. Schouten, R. A. Goldbohm, and P. A. van den Brandt, "Alcohol consumption, cigarette smoking and risk of subtypes of oesophageal and gastric cancer: a prospective cohort study," Gut, vol. 59, no. 01, pp. 39-48, 2010.

[21] H.-Z. Zhang, G.-F. Jin, and H.-B. Shen, "Epidemiologic differences in esophageal cancer between Asian and Western populations," Chinese Journal of Cancer, vol. 31, no. 6, pp. 281-286, 2012.

[22] P. C. Austin and L. J. Brunner, "Inflation of the type I error rate when a continuous confounding variable is categorized in logistic regression analyses," Statistics in Medicine, vol. 23, no. 7, pp. 1159-1178, 2004. 